\title{
An Institutional Foundation for the Knowledge Economy in Central and East European Countries
}

\author{
MATJAŽ NAHTIGAL \\ University of Primorska, Slovenia \\ matjaz.nahtigal@fm-kp.si \\ ISAAC STANLEY \\ NESTA, United Kingdom \\ isaac.stanley@nesta.org.uk
}

The purpose of this research is to provide an institutional framework - economic, legal, regulatory, educational - for the Central and East European countries aspiring to reach the levels of inclusive knowledge of economy and society known in some of the most developed regions in the world. The challenge to reach such a level of development is twofold. Even in the most developed parts of the world a growing gap can be observed between the technologically, organizationally and financially advanced firms and the rest of the economy. A strong concentration of knowledge, technologies, and organization of advanced production is taking place in only a handful of leading regions. The rest of the economy and society remains organized in traditional economic, social and managerial practices. The challenge for the policy-makers in these advanced economies and societies is how to disseminate these advanced practices to the excluded sectors of the economy and society. As shown by a recent NESTA report on knowledge economy, such a restructuring would require a major shift in institutional organization of the market economy. Strengthening of competition policy, improvements in technological policies, decentralized strategic partnership between the public and private sectors, and institutional innovations in ownership structures are necessary elements in spreading the benefits of the knowledge economy to the overall economy and society. From the perspective of developing countries, including the current and prospective $\mathrm{EU}$ members in Central, Eastern and Southern Europe, the task in front of the policy-makers is even more challenging: how to overcome the development gap between the developed and developing countries; how to overcome the path dependency; and how to establish an inclusive modern knowledge economy and society. Only high-quality public institutions, an accountable and proactive public sector, strategic decentralized coordination between 
the public and private sectors, and institutional imagination can lead to such a path of inclusive development. The probability of climbing from the (semi) periphery appears increasingly low after several decades of missed opportunities during the period of transition, but the stakes are high. Only the successful institutional, economic and social restructuring of developing countries can lead toward a more balanced, more sustainable and more diverse development of the world economy.

Key words: Central and Eastern Europe, knowledge economy, variety of institutional financial models, institutional innovations https://doi.org/10.26493/1854-4231.14.272-287

\section{Introduction}

The path of Central and Eastern European (CEE) countries, towards democracy and market economy, was once widely assumed to be smooth and inevitable. It has in the event been arduous, uncertain and inconclusive. Even after three decades since the fall of the Berlin wall, and despite the efforts of several generations of reformers, countries in the region - current members and prospective members of the European Union ( $\mathrm{EU})$ - have been unable to reach $\mathrm{EU}$ average levels of socio-economic development. Although the pathways and experience with the transition, post-transition and integration with the $\mathrm{EU}$ have differed significantly, the fact remains that the distance to the $\mathrm{EU}-28$ development average remains significant.

The purpose of this article is not, however, to discuss the successes, failures and missed opportunities of the countries in the region, but to point to one important international process of development that may offer new opportunities, if properly understood and incorporated, or new obstacles if misunderstood and ignored. Namely, the discussion in this article is going to be devoted to the rapid development of the knowledge economy in the leading global economies. The characteristics of these processes will be briefly presented, and the implications for developed economies will be considered. In the following section, the implications for developing countries will be discussed. The final section will return to developing countries, and explores the kinds of institutional innovation which might enable the reshaping of their legal, economic and social environment to underpin a more inclusive form of development.

A point of departure for the discussion is our contention that the mere institutional emulation of the advanced market economies and developed parliamentary democracies will not in itself translate into

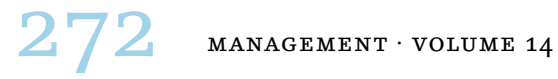


economic, technological and social convergence with these selectively or randomly chosen exemplars. The mere mechanical process of copying and implementing institutional frameworks is unlikely to foster technological progress, socially inclusive growth democracy, or even dynamic market economies. Even the successful examples of adoption have required creativity and institutional imagination to transfer a certain set of economic, social and legal institutions meaningfully from one context to another.

A notable voice to draw attention to the shortcomings of the mere mechanical transfer of institutional solutions was Joseph Stiglitz during his terms as a vice-president of the World Bank. The World Bank itself was heavily involved in the process of transition, mass privatization, macro-economic stabilization and the establishment of social welfare as a mere residual for the citizens, unable to compete on the markets. In his critique of the mechanical approach to the largescale institutional transformation, Stiglitz emphasized that, without clearly defined social goals, without more instruments and policytools, and without close cooperation between the public and private sectors, the transition process for the countries in Central and Eastern Europe would not lead to inclusive, socially cohesive and competitive economies (Stiglitz 1998). Even twenty years after this critique and set of alternative proposals for the transition process, his insights remain inadequately understood.

In one of the more comprehensive and systemic regional studies of transition Milica Uvalic and Daniel Vaughan-Whitehead, show how inadequately designed large-scale institutional reforms had a number of unforeseen consequences in the region. Their comparative study of the outcomes of privatization at the peak of this process identifies that, contrary to the expectations of reformers and international organizations, employee-owned companies were run more successfully than many other types of privatized companies (Uvalic and Vaughan-Whitehead 1997). Of course, it might be claimed that large-scale institutional transformation is a matter of time - that it takes time for new institutional framework to become established, that it takes time for actors to adjust, and that it takes time for policy-makers, regulatory authorities and the judiciary to adopt and enforce new rules, standards and conduct. Such a claim, however, is inadequate to explain the persisting gap between developed and CEE economies three decades since the beginning of the transition. The distinction between the core and periphery of Europe has indeed widened during the protracted financial crisis and its aftermath (Nikolovska and Mamucevska 2015). 
The comparative literature on the variety of institutional models (Hall and Soskice 2001, Schmidt 2002) suggests there is no one single, universally valid institutional framework for a market economy, parliamentary democracy and organized civil society. Different countries developed their institutional models and their economic, technological, social and educational policies to develop prosperous, competitive economies and cohesive societies. Some countries in different historical instances even moved from one institutional setting to another to counter adverse international and domestic economics and financial and social circumstances. A notable example of such a transition was the adoption of the New Deal project with the establishment of new institutions, such as the Stock and Exchange Commission to regulate and supervise financial markets; the Federal Deposit Insurance Corporation to protect the savings of the citizens and small businesses; and the Social Security Administration to provide basic economic and social security to its citizens. These are examples of how even large, developed countries can deviate from one institutional model previously based on a 'laissez-faire' economy and the minimum role of the government to cope with comprehensive economic and social distress. Moreover, between two opposites, between the 'laissez-faire' approach and 'dirigiste' strong interventionist state, there is a broad territory in which different countries can develop different institutional models capable of various interactions between the public and the private sectors, between the financial institutions and the markets, and among education, science and research. Even in the context of European harmonization and of globalization, and despite the constraining effect of European and international economic legal order, the developed countries have retained a certain level of autonomy in steering their overall development.

To develop, advance and innovate, then, ceE countries need the opportunity to reimagine and reshape their own economic and democratic institutions (Visvizi 2018). This has not generally occurred during the period of transition and $\mathrm{EU}$ accession. There are important differences between the countries in the region, but the ability to develop and transform institutions has been very limited. This inability has long term implications for the entire region. Despite the scarcity of resources at the disposal and of the stock of capital inherited from previous periods, a more strategic and better implemented approach to institutional change could be decisive in securing more inclusive, transparent and competitive development throughout the region. The capacity to build distinctive and

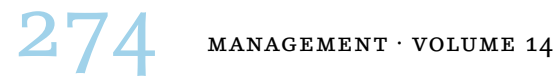


high-quality institutions $\mathrm{n}$ may be decisive in marshalling limited resources toward socially inclusive, innovative and balanced overall development.

During the financial crisis, countries in the region suffered from economic recession, capital flight, and social welfare erosion. As noted by Pržiklas Družeta and Škare, a European implementation of austerity without taking into account weak economies and diversity across the $\mathrm{EU}$ led to the elimination of the welfare state. Without the existence of a welfare state, it is not possible 'to achieve sustainable long-term growth and decrease of the deficit' (Pržiklas Družeta and Škare 2017, 113). In other words, the opportunities for the countries in the region to reach the average $\mathrm{EU}$ development after the financial crisis and the period of austerity are even fewer, because the distance has widened, and the advanced European societies invest and develop new innovative models of knowledge economy and knowledge-based societies at an accelerating pace. This enables them to capture all of the benefits of innovative leaders in many segments of high value-added markets.

Therefore, the challenge for the new generation of reformers in the region is to determine how to develop institutional capacities and how to adjust towards a sectorally diverse knowledge economy before being permanently pushed into the position of supplying relatively cheap labor and remaining stuck with the traditional forms of production, industry and services. A handful of firms, entrepreneurs and experts may succeed in integrating with the advanced forms of production and innovation, while large segments of society are permanently excluded from the benefits and opportunities of the knowledge economy. In short, a European socio-economic cleavage between core and (semi) periphery risks becoming permanent. To reverse this trend, no matter how complex or challenging it may be, the economies and societies in the region need to develop institutional capacities to cooperate and support innovation, both within new high-value sectors, and established lower-value ones (in which the bulk of the population will continue to work).

\section{The Knowledge Economy and its Implications for the Developed Countries}

Before entering into the discussion on the knowledge economy in advanced economies, it is important to note out that advanced economies often pursue more elaborate, although less visible, industrial and innovation policies policies than those often recommended to developing countries. Unlike the standard repertoire of measures 
for the developing countries - namely macroeconomic stabilization, privatization, liberalization, and a residual social safety net - most, if not all, advanced economies pursue many more innovative policies, and they often develop more innovative institutions beyond the traditional framework of a market economy and a traditional parliamentary democracy. As noted by Marianne Mazzucato in The Entrepreneurial State (2013) even the United States, the most internationally advanced liberal market economy, pursues many policies and creates many public institutions in support of technological advancement and in strengthening a competitive edge. Mazzucato (2013, Introduction, Chapter 3) extensively explored us research and technological public policies and pointed out that, 'despite common perceptions, there the State has been extremely proactive and entrepreneurial in the development and commercialization of new technologies.' In her research, she cites and analyses many examples of us federal government proactive policies, such as that public spending accounts for 57 percent of basic research, while the private sector accounts for only 18 percent of spending. The ratio changes when applied research is included (Mazzucato 2013, Chapter 5). Mazzucato also provides a detailed account of key components integrated in Apple's famous iPods, iPads and iPhones. Her study points out that 'nearly every state-of-the-art technology [...] is an often overlooked and ignored achievement of the research efforts and funding support of the government and military.' (Mazzucato 2013. Chapter 5) Her detailed research of 12 major technologies integrated in the Apple products in no way diminishes the success of Apple's inventors, managers and visionaries, but it points to the fact that very frequently only long-term strategic coordination between the public and the private sectors can ultimately lead to a technological breakthrough on the global markets. This perspective should be maintained when we are discussing the role, organizational structure, and importance of the leading global technological giants.

There are hidden differences in institutional design, structural improvements, and policy-making approaches between the advanced economies and the economies that are trying to catch up to them in terms of overall development (Rodrik and Sabel 2019). These hidden differences are often poorly understood and analyzed by the reformers in Central and Eastern Europe. Therefore, more attention should be paid to the hidden differences in the area of institutional innovations and constant structural improvement, and less focus should be made on mechanical, superficial emulation of ready-made institutional structures.

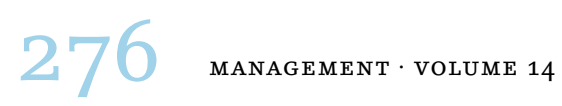


There is an ongoing discussion on the characteristics, opportunities and constraints of the knowledge economy (e.g. OECD 2019). Before going further, it is important to clarify what we mean by this term. The concept of the knowledge economy is frequently equated with the use of advanced technologies: digitization, AI, industry 4.0 or the Fourth Industrial Revolution (Roblek, Meško, and Krapež 2016). As Roberto Unger has forcefully argued, this concept focuses on the superficial signs of the knowledge economy - the 'gadgets' with which it may coincide - rather than its deeper, more radical features.

Fundamentally, the knowledge economy needs to be understood as a new mode of production. presents a radical break with Fordism. Traditional manufacturing assumes strong internal divisions of labor, narrowly defined tasks for semi-skilled workers, hierarchical division of work, and distance between task-defining and taskexecuting jobs. Rigid machinery assumes routine and repetitive work, where the main focus is on constant improvements of efficiency and the constant search for possible cost reductions.

In contrast, the knowledge economy is much more collaborative. It assumes teams of workers, experts and managers making constant efforts to innovate and improve processes of production and products. Multi-purpose machines require a skillful workforce capable of multiple tasks and operations. Between different layers of workers and teams of workers a constant flow of information is established, and the traditional distinction between task-defining and task-executing jobs is blurred. The aim of production is not primarily to minimize costs per unit of work hour but to improve the quality of a tailor-made product for the known customer. Instead of a high volume of standardized products, small volumes of high-quality tailor-made products are produced. Rapid changes in the process of production require cooperation of workers and constant adjustments and improvements that are best described as a constant learning process. Production comes, in short, to approximate the workings of the human imagination.

The advantages of the described radical break with the traditional production are flexibility as a response to uncertain market fluctuation, an environment conducive to permanent innovation, and a workplace that rewards creativity, innovation and cooperation. A knowledge economy in which many could take part holds the promise of advancing human wellbeing and self-realisation, through much broader access to creative and fulfilling work.

One of the crucial distinctions between fordism and the knowl- 
edge economy is a paradigm shift which was deemed conceptually impossible to achieve within the normative and institutional context of the traditional mode of production. There is growing empirical and theoretical evidence that the traditional economic principle of diminishing returns no longer strictly applies to the context of the knowledge economy. The constant experimentation in production and continuous innovations, as opposed to episodic innovations and scientific breakthroughs in the realm of traditional mass production, can, according to Unger, 'translate scientific discovery and technological invention more directly and continuously into productive activity than it ever could before.' (Mangabeira Unger 2019, 30-31). Researchers, policy-makers, managers, workers and other stakeholders in the most developed countries in the world are gradually becoming aware of the immense potential that the knowledge economy might bring to their societies conceptually, institutionally, normatively and practically.

There is, however, a major obstacle in disseminating the opportunities and benefits of the knowledge economy. It relates to the insufficient understanding of opportunities and the insufficient changes in the conceptual, institutional and educational environment that would enable broad dissemination of advanced technologies, knowhow, and skills to the society at large. The new mode of production is not limited to high-tech manufacturing, and can be observed in a wide range of sectors, including services and agriculture. As Mangabeira Unger $(2019,1)$ notes, however, 'in every sector of the economy [...] it remains a narrow fringe, excluding the vast majority of the labor force.' It is confined and insulated from the large segments of backward economies. Without a proper institutional framework, a handful of the most competitive and innovative companies is dominating global markets in many segments of the economy, whereby a majority of firms lack incentives to invest due to their inability to achieve expected returns on their investment. The gap between this handful of dominant large corporations and the rest of the economy is immense. An oECD study of the world's 2,00o largest corporate investors in $\mathrm{R} \& \mathrm{D}$ found that the top 5 percent of these companies accounted for 55 percent of their total R\&D expenditure (OECD 2017).

The confinement of the tiny segment of dominant large corporations - a modern version of the kingdoms within kingdoms, as succinctly described by Roberto Mangabeira Unger - presents an organizational and spatial concentration of cutting edge technologies, finance, research and know-how in the hands of the few largest com-

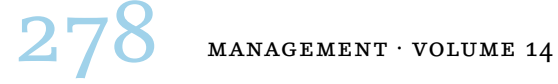


panies, which have all of the necessary resources and possibilities to grow, innovate and develop even further. For them, the laws of constant returns do not apply. Instead, due to their constant innovations and improvements, their competitive edge created and maintained through large investments in $\mathrm{R} \& \mathrm{D}$, and takeovers that were largely unchallenged by the authorities, a law of increasing returns applies. Due to the insular character of the present form of the knowledge economy in the most developed countries in the world, the new principle of 'the winner takes all' comes closest to the practice than ever before. While benefits and opportunities are consequently highly limited to the narrow circles of economy and society, the overall social benefits, beyond the benefits of being consumers of advanced products and services, are much less tangible. The aggregate level of investments remains low, overall productivity remains stagnant, and social and regional inequalities increase.

The confined character of the knowledge economy, its potential and its constraints are gradually receiving more attention from policy-makers and international organizations in developed countries. Proposals such as the rigorous implementation of the competition policy, improved technological policies beyond the entrenched circles of recipients, high quality education and skills systems, and new types of modern industrial policies increasingly discussed. To exploit the opportunities of the knowledge economy for society as a whole and to overcome its confined character, the theoretical and practical discussions are moving beyond standard models of the market economy, of the role of government, of representative democracy and of the role of organized civil society. A whole new set of institutions should be envisaged to reorganize the market economy, representative democracy and civil society to be capable of exploiting the opportunities and benefits of the knowledge economy while overcoming the constraints and confinements of the knowledge economy in the current institutional framework. The current institutional framework, which is skewed toward the concentration of benefits and opportunities in the hands of a handful of the largest corporations in the world, is too narrow to allow a necessary transformation toward an inclusive knowledge economy - or a knowledge economy 'for the many.'

Significant institutional innovations are increasingly being proposed, discussed and sometimes implemented (especially at municipal level) by thinkers and political actors in developed countries around the world. Examples include new public institutions for industrial policy, new financial institutions capable of providing long- 
term finance to SMES, new forms of property regimes and competition regimes, new labor market institutions to support life-long learning and the ongoing re-skilling of workers, new approaches to corporate governance moving away from shareholder value maximization as the guiding principle, and new forms of innovation to improve conditions, job quality and pay in the 'foundational economy' (including many everyday, low-value sectors). The extent of institutional innovations and their scope and speed may determine the ability of these advanced countries to broaden and widen benefits of the knowledge economy from insulated minorities to the many other participants and stakeholders.

\section{The Implications for the Developing Countries and $\mathrm{CEE}$ Countries}

The previous evoked some of the challenges faced by highly developed countries in addressing the implications of knowledge economy context for society at large. Some of the challenges require comprehensive structural rethinking of the standard model of the market economy, of traditional legal institutions supporting the standard model of a market economy, such as property rights, contracts, and forms of corporations, and the redefined role and relation between the public and private sectors. These challenges are immense and are in parallel with the immense opportunities and constraints of the rapidly evolving knowledge economy.

What then are the implications for developing countries? How can the middle-income countries in Central and Eastern Europe face the challenge of transforming their economies and societies in the context of opportunities and constraints of the knowledge economy (Nahtigal 2004)?

The developing countries, including the CEE countries even after joining the $\mathrm{EU}$, face many additional challenges in comparison with the advanced economies. To name just a few of their additional hurdles, many industrial sectors are insufficiently competitive, investments in R\&D, education and technological progress are insufficient, generally poorer quality of infrastructure, lack of public funding, relatively poorer quality of governance, lack of transparency and accountability of public institutions, and difficulties with access of their products to the world's leading markets.

Policy space for the developing countries in the context of globalization and the international legal order has become very narrow. Only a handful of developing countries in the recent decades were able to find a pathway from the socio-economic periphery. For the

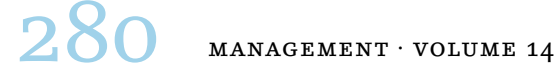


majority of developing countries, climbing the ladder of industrial, social and overall development appears to remain an unattainable goal, sometimes due to domestic conditions, sometimes due to international conditions and most often as a consequence of normative, conceptual and practical constraints at both domestic and international level. These described constraints do not mean that, even in the poorest and deprived regions around the world, domestic governance and high-quality public institutions cannot be established. Comparative studies have shown that, even in some of the poorest and remote regions in the developing world, such as Ceara in Brazil and Kerala in India, the quality, transparency and accountability of public institutions can secure relatively inclusive development and offer opportunities even to the very poor segments of society and the economy (Evans 1995, 235-40; Tendler 1997).

As a significant complicating factor the contemporary context of globalization and the international legal order, the rise of China as the largest of the fast-developing countries in the world must also be mentioned. Its economic rise in the last few decades deserves special study and focus far beyond the present contribution. On one hand, it serves as an example of a large developing country capable of successful integration with the world economy. On the other hand, it is certain that, without the trade openness of the Western world, its path of development would look substantially different. At present, China is as much an example of a successful pathway from the periphery as it is a source of uncertainty about the extent to which it will contribute to the current and future global imbalances in terms of trade, financial flows, labor and environmental standards.

The rise of China complicates our discussion, because its success overshadows the difficulties, constraints and stagnation of many other developing and middle-income countries around the world. Among them are the countries of Latin and Central America, Central Asia, Mediterranean and sub-Saharan countries and the countries in Central and Eastern Europe.

Despite three decades of large-scale institutional reforms and despite the fact that many of the countries in CEE have become member states of the $\mathrm{EU}$ in 2004, none of the countries have reached the average level of development in the $\mathrm{EU}-28$. The slow process of convergence with the average $\mathrm{EU}$ development is a source of concern, and it should be also an object of comprehensive analysis. The protracted financial crisis in the Eurozone and the subsequent slow, uneven recovery only contributed to the entrenchment of the cleavages in the $\mathrm{EU}-28$. 
Similar to the constraints of many developing countries, the CEE countries are facing so many imminent economic and social challenges that the rapid evolvement of the knowledge economy in the leading parts of the world is escaping their proper attention. Policymakers in the CEE countries are insufficiently aware of the opportunities and new set of constraints that the knowledge economy presents in its current form.

Just to cite one piece of empirical evidence to illustrate better this claim in the European context, we can take a closer look at the Eurostat Regional Yearbook 2018 in a chapter on R\&D. This chapter reveals considerable regional disparities from the current perspective, and it offers a glimpse of the most probable future regional trends across the $\mathrm{EU}-28$. The report points to the present and future imbalances, as relatively few regions recorded high levels of R\&D intensity, and a much higher number of regions have relatively low levels of $R \& D$ intensity: '208 out of 272 NUTS 2 level regions recorded an R\&D intensity that was below the $\mathrm{EU}-28$ average of 2,04 percent' (European Union 2018, 118).

To put this empirical observation in the current European context, we understand better that the current and future developments lead to rigid hierarchical segmentation and concentration of economic development in a selected number of core European regions. To reverse this trend, a coordinated effort by supra-national, national and regional actors would be necessary to shift the trends toward more dissemination of knowledge, skills and all other necessary resources to capture the benefits of the knowledge economy for the many (Mazzucato 2018).

This is not to say that one single indicator, irrespective of its importance, presents firm evidence of persistent regional divergences. Moreover, this empirical indicator does not imply uncritical call for more R\&D investments in stagnant and backward regions across the $\mathrm{EU}-28$. Theoretical and empirical research teaches that there is no automatic and guaranteed link between increased $\mathrm{R} \& \mathrm{D}$ investments and inclusive growth. Without simultaneous and coordinated efforts to build the capabilities of firms, especially small and medium sized firms, newly created knowledge, technologies and re-skilled workers will not be put to productive use (Mangabeira Unger 1997, 12; Mangabeira Unger et al. 2019). Without attention to firms working across a wide range of sectors - including the lower-value foundational and neglected sectors in which the majority in all economies work, the benefits of innovation will inevitably be confined to a small minority (Foundational Economy Collective 2018).

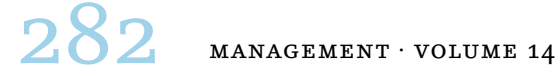


The challenge ahead of policy-makers and CEE countries in general is at least twofold: first to grasp the importance and characteristics of the rapidly changing contemporary knowledge economy, and to reimagine institutional framework to ensure that economic and social participation in the knowledge economy is as broad as possible. In the previous section, we saw that the latter presents a major, almost insurmountable challenge even for the most advanced countries in the world. An additional handicap for the new generation of reformers in CEE countries stems from the period of transition, when large-scale mass privatization often led to systemic fraud, widespread corruption and the general erosion of trust among citizens, entrepreneurs and civil society (Reinsberg et al. 2019; Pavlovic 2019).

In such a highly constraining context, a redirection of the general pattern of socio-economic would require the following the CEE countries to stop mechanically emulating the standard/ideal model of market economy. It is not possible to catch up with the advanced economies and societies by merely emulating their institutional framework at a very superficial level. Each of the advanced economies has developed its own distinctive model of socioeconomic development with its own achievements and deficiencies. None of these models are static and unchangeable. Even the most advanced economies and societies are constantly trying to develop further and innovate their models with a variable degree of success and also failure. Therefore, from the perspective of CEE reformers and from the broader international perspective of the developing countries, more important than emulating a presupposed ideal type of market economy model is to identify and carefully select the most inspiring and innovative development models from around the world and then use their own imagination and creativity to develop their own innovative developmental models. Such embedded developmental models should primarily capture productive potential and comparative advantages of their own local communities, regions and countries before becoming fully integrated with the common European market and global markets.

On the path of redirection of CEE economies and societies, a trust between public institutions, policy-makers, entrepreneurs, experts and independent stakeholders must be restored. The best way to restore trust among key social actors from the public and private sectors is to have a clear sense of redirection of development, to reach a commonly articulated development strategy, and to have transparency and accountability. In so doing, a decentralized and strategic 
coordination of public and private development plans can present a first step toward an inclusive knowledge economy.

The ability to analyze, understand and disseminate the best practices, technologies, know-how, and organizational improvements from the advanced companies to the rest of the economy is one of the most important abilities of the proactive public sector. A set of decentralized institutions, such as regional support centers, centers for retraining and re-skilling, new regional financial institutions providing long-term support for start-ups, for small and medium size companies should be established. These decentralized institutions should retain a sufficient level of professional autonomy to impose financial discipline and competition among networks of small and medium sized companies. It should not be imagined, however, that the task of promoting innovation among SMEs will always be a question of disseminating advanced technologies and raising productivity through increased output; in many increasingly important foundational economy sectors, such as social care, it is social innovation to improve business models, service models and ultimately dignity in work that will be the priority (Burns et al., 2016; Foundational Economy Collective 2018).

New forms of competition at the regional level among small and medium sized companies should be developed to spur competition and ability to cooperate at the same time. Networks of small and medium sized companies can combine decentralized initiative, constant innovations and improvements with scale under coordination with the public institutions. In such a way, regional networks of small and medium sized companies can be sufficiently robust to counter market uncertainties, instabilities and competition with large, Fordist companies in regional and international markets.

Decentralization, redirection and restructuring of regional economies by activating and reinventing local potential cannot be complete without further institutional innovations in property and ownership regimes. Contrary to the traditional, unified and increasingly concentrated property regime, a spread of property rights to the large parts of the local and regional populations to the variety of stakeholders (public pension funds, local governments, workers ...) can lead to new forms of ownership structures, cooperation and institutional innovations. Overlapping property regimes can open access to more participation, more entrepreneurship, and more initiatives than the currently rigid and concentrated forms of ownership presuppose.

Redirection of the knowledge economy for the many is primarily 
a redirection from the current development of the economy and society in its hierarchical segmentation, concentration of knowledge, finance, technology and skills toward the dissemination of these resources to the stagnant and backward regions. It is a challenge in the context of advanced economies, and it is an even more demanding challenge in the context of developing and middle-income countries, such as the CEE countries.

\section{Conclusion}

Understanding the characteristics, opportunities and constraints of the knowledge economy presents one of the most crucial theoretical and practical discussions at of our time. How this discussion will be addressed and resolved will depend on future socio-economic development in many parts of the world, developed and developing. Advanced economies, experts and international organizations took a lead, although with currently few tangible structural improvements. Inertia, vested interests and the tendency toward maintaining the status-quo all present obstacles to innovations in economic policies, education, innovation policies, and competition policies let alone institutional innovations of the market economy toward democratized access to the necessary resources and support for inclusive, sustainable and balanced knowledge economy in the future. Nevertheless, there are some encouraging regional examples that confirm the possibilities of alternative futures beyond stagnation, exclusion and inequality.

In contrast, the situation in the developing parts of the world, including the middle-income CEE countries, is more complicated. There is even greater need to discuss new possibilities, new opportunities and real constraints. After decades of internalizing a belief that there is one single, universally valid and universally applicable model of market economy that needs to be introduced their economies and societies and decades of mere emulation that apparently does not lead to more inclusive and more balanced development, the time has come for deep consideration of new ways based on more creativity and institutional imagination. Even in the most demanding circumstances of the developing world and in the most deprived areas, certain exceptional examples of good, transparent and accountable governance show that a restructuring toward more inclusive and more sustainable development is possible. Successful examples of transformation from the developing parts of the world and from some of the most developed parts of the world should be viewed as a source of inspiration, information and encouragement 
that structural transformation toward an inclusive knowledge economy is the next possible pattern of development for many other developing and $\mathrm{CEE}$ countries.

\section{References}

Burns, D., J. Earle, P. Folkman, J. Froud, P. Hyde, S. Johal, I. R. Jones, A. Killett, and K. Williams. 2016. 'Why We Need Social Innovation in Home Care for Older People.' cresc Public Interest Report, Centre for Research on Socio-Cultural Change, Manchester.

European Union. 2018. Eurostat Regional Yearbook: 2018 Edition. Luxembourg: Publications Office of the European Union.

Evans, P. 1995. Embedded Autonomy: States And Industrial Transformation. Princeton, NJ: Princeton University Press.

Foundational Economy Collective. 2018. Foundational Economy: The Infrastructure of Everyday Life. Manchester: Manchester University Press.

Hall, P. A., and D. Soskice. 2001. Varieties of Capitalism: The Institutional Foundations of Comparative Capitalism. Oxford: Oxford University Press.

Mazzucato, M. 2013. The Entrepreneurial State: Debunking Public vs. Private Sector Myths. London: Anthem Press.

- 2018. Mission-Oriented Research \& Innovation in the European Union: A Problem-Solving Approach to Fuel Innovation-Led Growth. Brussels: European Commission.

Mangabeira Unger, R. 1997. What Should Legal Analysis Become? London: Verso.

. 2019. The Knowledge Economy. London: Verso.

Mangabeira Unger, R., I. Stanley, M. Gabriel, and G. Mulgan. 2019. Imagination Unleashed: Democratising the Knowledge Economy. London: Nesta.

Nahtigal, M. 2004. A Decade of Transition and Beyond. Ljubljana: Fakulteta za družbene vede Univerze v Ljubljani.

Nikolovska, N., and D. Mamucevska. 2015. 'Current Crisis in the EU in the Light of the Contradictions of the Core - Periphery Development Model.' Review of Innovation and Competitiveness 1 (1): 4-62.

- 2017. OEcD Science, Technology and Industry Scoreboard 2017: The Digital Transformation. Paris: OECD.

- 2019. 'New Approaches to Economic Challenges.' https://www .oecd.org/naec/projects/.

Pavlovic, D. 2019. 'When Do Neoliberal Economic Reforms Cause Democratic Decline? Evidence from the Post-communist Southeast Europe.' Post-Communist Economies 31 (5): 671-97.

Pržiklas Družeta, R. and M. Škare. 2017. 'Fiscal Austerity Policy Impact on Welfare.' Review of Innovation and Competitiveness 3 (1): 99-118. 
Roblek, V., M. Meško, and A. Krapež. 2016. 'A Complex View of Industry 4.o.' Sage Open (April-June): 1-11.

Rodrik, D., and C. Sabel. 2019. 'An Industrial Policy for Good Jobs.' https://www.project-syndicate.org/commentary/industrial-policy -for-good-jobs-by-dani-rodrik-and-charles-sabel-2019-05?barrier $=$ accesspaylog

Reinsberg, B., T. Stubbs, A. Kentikelenis, and L. King. 2019. 'Bad Governance: How Privatization Increases Corruption in the Developing World.' Regulation \& Governance (June). https://doi.org/10.1111/rego .12265

Schmidt, V. A. 2002. The Futures of European Capitalism. Oxford: Oxford University Press.

Stiglitz, J. 1998. 'More Instruments and Broader Goals: Moving toward the Post-Washington Consensus.' Speech in UNU WIDER, Helsinki.

Tendler, J. 1997. Good Government in the Tropics. Baltimore, MD: John Hopkins University Press.

Uvalic, M., and D. Vaughan-Whitehead. 1997. Privatization Surprises in Transition Economies: Employee-Ownership in Central and Eastern Europe. Cheltenham: Edgar Elgar.

Visvizi, A. 2018. 'Central Europe: Competitiveness through Innovation and Collaboration.' Yearbook of the Institute of East-Central Europe 16 (3): 7-12. 